\title{
Ano Temático da Avaliação Psicológica: uma discussão importante sobre direitos humanos, prática e formação
}

\author{
Rodolfo A. M. Ambiell - Universidade São Francisco, Itatiba, Brasil
}

Conselho Federal de Psicologia (2011). Ano da avaliação psicológica: textos geradores. 156 p. Brasília: Conselho Federal de Psicologia.

O ano de 2011 inicia a segunda década do século XXI, celebrando importantes conquistas da psicologia na década passada, especialmente no tocante à avaliação psicológica. Entre 2001 e 2010 a área, que é a única de atuação exclusiva do psicólogo, passou por profundas transformações e avanços técnicos e científicos que, se por um lado, promoveram mudanças significativas em relação à sua imagem social tanto dentro quanto fora do âmbito profissional da psicologia, por outro, levantaram questões importantes sobre a área. Como fruto dessas mudanças e no intuito de responder a algumas das perguntas levantadas, o Conselho Federal de Psicologia (CFP), por meio da Assembleia das Políticas, da Administração e das Finanças (APAF), instância deliberativa do Sistema de Conselhos de Psicologia, decidiu instituir 2011 como o Ano Temático da Avaliação Psicológica, um tempo precioso para discussões e reflexões sobre a prática da avaliação na Psicologia brasileira.

A adoção de anos temáticos tem sido feita pelo CFP desde 2006, e já foram abordadas as relações da psicologia com a saúde e a educação, bem como a prática da psicoterapia. Ao longo do ano temático são promovidas atividades nas sedes e subsedes dos conselhos regionais, bem como no próprio CFP, buscando refletir sobre questões relativas aos temas. Neste ano, as atividades presenciais têm ocorrido Brasil a fora desde o mês de agosto, que podem ser acompanhadas pelo blog http://anotematico.cfp.org.br/2011/. No mesmo endereço eletrônico, o leitor também pode baixar o arquivo em PDF do livro Ano da avaliação psicológica: textos geradores, organizado pelo Grupo de Trabalho do Ano Temático da Avaliação Psicológica, e que será resenhado nas linhas que seguem.

A obra, que conta com autores de renome da psicologia brasileira, é dividida em 22 textos organizados nos três eixos norteadores das discussões, que são: Qualificação: critérios de reconhecimento e validação a partir dos direitos humanos (eixo 1), Avaliação psicológica em contextos institucionais (eixo 2) e Relação com o contexto de formação (eixo 3). A seguir, cada texto será brevemente apresentado.

\footnotetext{
${ }^{1}$ E-mail: rodolfo.ambiel@usf.edu.br
}

Abrindo a coletânea a respeito do eixo 1, Acácia A. A. dos Santos, da Universidade São Francisco, faz um breve histórico da área no Brasil, especialmente na última década, em "O possível e o necessário no processo de avaliação psicológica". No texto, a autora reflete sobre a importância que a avaliação tem para a psicologia enquanto forma de inserção e prestação de serviços à sociedade e, sendo uma tarefa da qual os profissionais não podem abrir mão, a urgência na necessidade de qualificação dos psicólogos para tal tarefa. Alexandra Ayach Anache, da Universidade Federal do Mato Grosso do Sul, apresenta "Notas introdutórias sobre os critérios de validação da avaliação psicológica na perspectiva dos Direitos Humanos". A discussão nesse texto vai no sentido de que novos estudos sobre as teorias e metodologias que embasam os instrumentos e os processos de avaliação psicológica deveriam ajudar a fomentar a diminuição das desigualdades sociais, considerando os aspectos históricos imbricados na constituição de certos grupos. Dando continuidade a essa discussão, o terceiro texto, "Qualificação da avaliação psicológica: critérios de reconhecimento e validação a partir dos Direitos Humanos", de Caroline Tozzi Reppold (Fundação Universidade Federal de Ciências da Saúde de Porto Alegre), atrela a questão dos direitos humanos, no ponto de vista da psicologia, ao próprio código de ética da profissão, uma vez que a prática da avaliação psicológica é contemplada em diversos pontos do código. A autora assente, ao concluir, que o reconhecimento da avaliação psicológica como uma área de especialidade do psicólogo pode contribuir para atuações menos imperitas e com melhores frutos para a sociedade.

O psicólogo clínico Otávio de Abreu Leite, em "A medida no exame psicológico: reflexões sobre o significado clínico da medida" faz uma breve recuperação de conceitos psicométricos, especialmente daqueles utilizados na interpretação dos escores e, em seguida, reflete sobre a utilização compreensiva dos resultados de testes em situações clínicas, integrando-os com dados de outras técnicas e fontes de informação. "Avaliação psicológica, fundamentos e processo" de José Novaes, da Universidade Federal Fluminense, aborda a questão dos direitos humanos no processo de avaliação e na devolução e uso de seus resultados, e, 
indo além, sugere que a questão ética deve ser anterior à técnica no processo de desenvolvimento de instrumentos e do processo de avaliação. Ilma Lopes Soares de Meirelles Siqueira e Mari Angela Calderari Oliveira, da Pontifícia Universidade Católica do Paraná, abordam "O processo de avaliação psicológica" de um ponto de vista prático, propondo um "roteiro" do trabalho, desde o recebimento da demanda até a devolução dos resultados, ressignificando o lugar dos testes nesse âmbito.

Encerrando os assuntos do primeiro eixo, há um texto que aborda a importância da formação para a melhoria da competências dos profissionais para uso dos instrumentos ("Responsabilidade e ética no uso de padrões de qualidade profissional na avaliação psicológica, de Ricardo Primi - Universidade São Francisco) e três que abordam a importância da especificação dos contextos de aplicação dos testes, que são "Manuais especificando seus contextos de aplicação e âmbitos de ação", de Claudio S. Hutz (Universidade Federal do Rio Grande do Sul), "Importância da especificação dos contextos de aplicação e propósitos nos manuais de testes psicológicos", de Carlos Nunes (Universidade Federal de Santa Catarina) e "Manuais: contextos de aplicação e âmbitos de ação", de Bartholomeu Tôrres Tróccoli e Luiz Pasquali (Universidade de Brasília). Tais textos problematizam de forma competente os conteúdos dos manuais de testes psicológicos, que, além da função de informar sobre a teoria do construto avaliado e as formas de aplicação, correção e interpretação dos testes, acabam sendo fontes praticamente exclusivas de consulta para os profissionais, que acabam se restringindo em um tipo de publicação que pode levar até duas décadas para se atualizar. Dessa forma, os autores desses textos concordam com a necessidade de se pensar em normas gerais que possam guiar a construção de novos manuais, incluindo claramente em sua descrição os contextos em que a tomada de decisão seja possível sem, contudo, tirar do psicólogo a responsabilidade de decidir sobre os instrumentos a utilizar, baseado em critérios técnicos.

Os textos relativos ao eixo 2 , que abordam a avaliação psicológica em contextos institucionais, se iniciam com a contribuição de Adriana Marcondes Machado, do Instituto de Psicologia da Universidade de São Paulo. Em "Avaliação psicológica e as relações institucionais", a autora discorre sobre a construção das relações institucionais como fruto da convivência de diferentes pessoas, ocorridas nos diferentes contextos, e acena com a afirmação de que a avaliação psicológica, ao invés de revelar verdades, produz realidades com potência para afetar os rumos da vida de uma pessoa. Em seguida, o grupo de trabalho sobre o sistema prisional da APAF tece "Reflexões sobre a avaliação psicológica no sistema prisional", focando a prática da perícia psicológica no contexto prisional, especialmente ao subsidiar o Judiciário para concessão de progressão de regime e outros benefícios. O posicionamento da APAF é no sentido de discutir a possibilidade e validade de tal prática por psicólogos.

Ainda sobre a prática da avaliação no contexto prisional, outros três textos abordam esse assunto, quais sejam, "Avaliação psicológica no contexto das instituições de justiça”, de Leila Maria Torraca de Brito (Universidade do Estado do Rio de Janeiro), "Ética e Direitos Humanos sob o crivo da avaliação psicológica: validade e fidedignidade em questão", de Pedro Paulo Gastalho de Bicalho (Universidade Federal do Rio de Janeiro) e "A avaliação psicológica no contexto jurídico", Sonia Liane Reichert Rovinski (psicóloga judiciária do Tribunal de Justiça do Rio Grande do Sul). Embasados em pontos de vistas distintos, os autores apresentam e discutem justificativas epistemológicas, éticas e técnicas em relação à avaliação psicológica no contexto forense e sobre a delicada relação dos psicólogos e demais profissionais de outras especialidades do contexto jurídico.

Os textos de Fabián Javier Marín Rueda, da Universidade São Francisco ("Psicologia do trânsito ou avaliação psicológica no trânsito: faz-se distinção no Brasil?") e Janaína Sant'Anna e Priscila Bastos, do Instituto de Psicologia do Trânsito \& Recursos Humanos ("Relações institucionais: a avaliação psicológica no contexto trânsito") discutem de forma crítica aquele que, possivelmente, seja contexto de aplicação da avaliação psicológica com maior visibilidade e penetração social, que é o trânsito. Os autores são unânimes em construir críticas bem fundamentadas em relação à atuação do psicólogo nessa área que, por muitas vezes, acaba se constituindo como um mero aplicador de testes e com uma prática estritamente tecnicista, sem considerar toda a complexidade do comportamento humano e da mobilidade urbana. Encerrando as discussões desse eixo, Maria Júlia Trevizan, da Pontifícia Universidade Católica do Paraná, traz ao leitor ideias sobre a atuação no contexto organizacional em "Contextos em que a avaliação se insere", concluindo que a prática do uso de instrumentos com a chancela do SATEPSI, por si só, não faz de alguém psicólogo, mas o que de fato legitima a prática da profissão é o uso que se faz dos resultados.

O terceiro e último eixo de discussões contido neste livro é em relação ao contexto de formação. "Repensando a formação em avaliação psicológica no Brasil" é a proposta de Denise Ruschel Bandeira (Universidade Federal do Rio Grande do Sul), na qual 
ressalta as mudanças ocorridas na formação nas últimas décadas quanto aos testes e processo de avaliação psicológica, mas lembra que os currículos têm sofrido constantes alterações. A autora finaliza o texto questionando a premissa de que qualquer profissional sairia preparado da universidade para a utilização de qualquer tipo de teste e sugerindo que, para determinados tipos de testes, os psicólogos somente poderiam se credenciar para uso após formação pósgraduada. Célia Maria Souto Maior de S. Fonseca, da Universidade Católica de Pernambuco, concorda com a carência de formação na área, e coloca isso como uma contradição, uma vez que se trata de atividade exclusiva do psicólogo. Além disso, ressalta a necessidade de ampliar o ensino e treino de práticas de redação de textos psicológicos provindos de avaliação, uma vez que tal prática, se mal feita, pode comprometer todo o trabalho. A contribuição de Vannúzia Leal Andrade Peres, da Pontifícia Universidade Católica de Goiás ("Avaliação psicológica: relação com o contexto de formação"), retrata um pouco de sua trajetória de 35 anos como docente, com enfoque no psicodiagnóstico infantil em diferentes contextos. Finalizando o livro, Suzane Schmidlin Löhr (Universidade Federal do Paraná), em "Avaliação psicológica na formação do profissional da Psicologia, algumas reflexões" fala sobre a importância da integração teórico-prática na formação do profissional de psicologia, discutindo que a interpretação de dados de um teste vai muito além da simples reprodução do manual, mas exige uma vivência que o estudante de psicologia deve ter ao longo da formação.

Assim, a intenção de resenhar o livro Ano da avaliação psicológica: textos geradores, organizado pelo CFP, é apresentar ao leitor a possibilidade de desfrutar de textos escritos pelas mãos de alguns dos mais experientes pesquisadores e práticos $\mathrm{da}$ área $\mathrm{da}$ avaliação psicológica e com a crítica contundente de outros autores, preocupados com a humanização da prática que, afinal de contas, é particular da profissão que prima pelo humano. Assim, ao abordar as questões, por vezes delicadas, de uma forma acessível e, ao mesmo tempo, técnica e profunda, os autores que contribuíram nessa obra ajudam a psicologia de forma geral a dar mais um passo à frente. Os textos aqui resenhados são ditos geradores - e de fato o são: geradores de crítica, de desconforto, de incômodo. E, por isso mesmo, são geradores de debates e reflexão sobre uma prática cotidiana do psicólogo. Que o Ano Temático da Avaliação Psicológica seja um período fértil de mudanças, geradas a partir da discussão franca das limitações e dos avanços da área.

Rodolfo A. M. Ambiel é psicólogo, mestre e doutorando pelo Programa de Pós-Graduação Stricto Sensu em Psicologia da Universidade São Francisco do Campus Itatiba, e docente de cursos de graduação e pós-graduação lato sensu de psicologia da mesma universidade. É também consultor externo de pesquisa da editora Casa do Psicólogo. 
